*Doutorando em Direito Político e Econômico pela Universidade Presbiteriana Mackenzie (UPM) E-mail: jeferson@joliveiraadv. com.br

**Doutor em Direito pela Pontifícia Universidade Católica de São Paulo (PUC/SP)

Professor em Direito da Universidade Nove de Julho (UNINOVE) E-mail: benamarcelo@gmail.com

\section{INFRAESTRUTURA DE TRANSPORTES: REESTRUTURAÇÃO COMO POLÍTICA DE DESENVOLVIMENTO NO BRASIL}

\author{
TRANSPORT INFRASTRUCTURE: RESTRUCTURING AS A \\ DEVELOPMENT POLICY IN BRAZIL
}

\section{Jeferson Sousa Oliveira* Marcelo Benacchio**}

Comocitar: OLIVEIRA, Jeferson Sousa;BENACCHIO, Marcelo. Infraestrutura de transportes: reestruturação como política de desenvolvimento no Brasil. Scientia Iuris, Londrina, v. 25, n. 2, p. 62-82, jul. 2021. DOI: 10.5433/21788189.2021v25n2p62. ISSN: $2178-8189$.

Resumo: Ao longo da história moderna, a infraestrutura de transportes se mostrou um importante elemento para o desenvolvimento do mercado interno, fato este que ganhou contornos internacionais com o advento da globalização. No entanto, para que se possa maximizar a eficiência dos modais, faz-se necessário que o Estado adote uma estratégia de desenvolvimento sólida, o que não se pode verificar no Brasil, notadamente em decorrência da falta de integração entre os mesmos. Assim, objetiva-se evidenciar a importância da reestruturação dos modais brasileiros, a fim de integrá-los em prol da eficiência logística e do aumento da competitividade nacional no mercado externo.

Palavras-Chave: infraestrutura; transportes; reestruturação; integração; desenvolvimento.

\begin{abstract}
Throughout modern history, transport infrastructure has proved to be an important element for the development of the domestic market, a fact that has gained international contours with the advent of globalization. However, in order to maximize the efficiency of the modes, it is necessary for the State to adopt a solid development strategy, which cannot be seen in Brazil, notably due to the lack of integration between them. Thus, the objective is to highlight the importance of restructuring Brazilian modes, in order to integrate them in favor of logistical efficiency and increased national competitiveness in the foreign market.
\end{abstract}

Keywords: infrastructure; transport; restructuring; integration; development. 


\section{INTRODUÇÃO}

O desenvolvimento sempre foi tido como um objetivo a ser alcançado por diversos países, ensejando estudos e debates a seu respeito, o que resultou em diferentes políticas econômicas e regulatórias por todo mundo.

Compreender as razões do subdesenvolvimento não é algo simples, mas que deve estar pautado em características próprias de cada Estado, visando, com isso, corrigir os fatores causadores da estagnação econômica.

Nesse contexto, o Brasil, enquanto economia emergente, demanda uma profunda análise dos fatores que podem auxiliar no seu desenvolvimento. Para isso, a infraestrutura de transportes se mostra um importante elemento deste processo, à medida em que torna as operações logísticas internas mais eficientes.

No entanto, para que se possa falar ganho de eficiência, a integração dos modais apresentase como algo de significativa essencialidade, viabilizando, inclusive, maior participação nacional no mercado externo.

O Brasil, por sua vez, conta com uma infraestrutura de transportes sucateada, desprovida de investimentos e integração, o que gera uma imediata necessidade de reestruturação física, técnica e regulatória, pautada em uma sólida estratégia de desenvolvimento.

O sucateamento dos modais no Brasil é fruto de diversas políticas de expansão, voltadas ao atendimento de necessidades específicas, sem qualquer planejamento a longo prazo, o que dificulta a percepção de investimentos públicos e privados em decorrência do elevado risco do empreendimento.

Desta forma, por se tratar de um setor sensível à economia nacional, ainda que não se constitua em um fim do desenvolvimento, mas em um elemento que o viabiliza, objetiva-se analisar a necessidade de reestruturar e integrar os modais de transporte no Brasil. Para tanto, utiliza-se o método dedutivo, através de análise bibliográfica e legislativa, a fim de estudar do tema ora proposto.

\section{DESENVOLVIMENTO E INFRAESTRUTURA}

Há décadas o tema "desenvolvimento" tem estado em voga, fazendo-se presente na pauta política de diversos países, sendo alvo de repetidos debates tanto nacional quanto internacionalmente.

Vê-se, atualmente, uma distinção teórica entre o desenvolvimento puramente econômico e o desenvolvimento social, os quais atuam de forma complementar para que se possa ter um real desenvolvimento nacional (OLIVEIRA, 2020).

Nesse sentido, destaca-se, por exemplo, a posição de Amartya Sen (2010, p. 24), que frisa a importância de "dar o devido valor aos mercados, mas também apreciar o papel de outras liberdades econômicas, sociais, e políticas que melhoram e enriquecem a vida que as pessoas podem levar".

Contudo, os debates sobre o desenvolvimento muitas vezes tomam contornos econômicos, 
haja vista se acreditar amplamente no papel instrumental do mercado para o crescimento no país.

Embora por muito tempo tenha-se acreditado que o subdesenvolvimento seria uma etapa necessária do processo de desenvolvimento, antecedendo-o, passou-se a compreender que tal assertiva não era verdadeira, haja vista esta condição ser fruto da soma de diferentes fatores históricos, políticos e econômicos (FURTADO, 2009),

Celso Furtado (2009, p. 172) explica que o subdesenvolvimento, por se tratar de um fenômeno específico, demanda uma teorização autônoma, não convindo explicá-la através de simples analogia à experiência dos países desenvolvidos.

Nesse sentido, é possível compreender que o estudo do subdesenvolvimento deve estar pautado em fatores e características próprias de cada Estado, individualmente considerado, de modo que sua estratégia de desenvolvimento seja capaz de suprir deficiências e atender aos anseios sociais.

O Brasil, por se tratar de um país economicamente emergente, não se excetua a esta afirmação, vez que necessita de uma ampla e profunda análise dos elementos que o impedem de atingir o pleno desenvolvimento socioeconômico.

Por adotar o capitalismo como seu sistema econômico, o Brasil detém o mercado interno como patrimônio nacional, sendo este responsável por viabilizar não apenas o já mencionado desenvolvimento socioeconômico, mas também a autonomia tecnológica do país (art. 219, CF) (BRASIL, 1988).

Mais do que isso, a Constituição Federal dispõe de diversos princípios e normas que visam reger o mercado interno, definindo a existência digna como um fim a ser assegurado pela ordem econômica (art. 170, CF). Claramente, tal objetivo tem por base a dignidade humana, a qual é tida como um dos fundamentos da República (art. 1º, III, CF) (BRASIL, 1988).

Os princípios da ordem econômica atuam não apenas como instrumentos norteadores das políticas econômicas, servindo também para orientar a atividade regulatória, tal qual dispõe o artigo 173, $\S 4^{\circ}$ da Constituição Federal, ao prever a repressão ao abuso do poder econômico (BRASIL, 1988).

Em outras palavras, diz-se que a atividade regulatória, bem como as políticas de desenvolvimento econômico, devem buscar proteger o mercado - e reflexamente a sociedade - ante sua importância para o desenvolvimento nacional, tomando por base os princípios constitucionalmente descritos, visando evitar a ocorrência de abusos e arbitrariedades por parte do Estado, o que resultaria em danos à economia em decorrência do excesso ou da ausência de sua atuação, gerando desequilíbrio entre os agentes econômicos e limitando a concorrência.

Daí a importância do Direito Econômico para o estudo de temas ligados ao desenvolvimento. Embora existam posicionamentos diversos no que se entende por Constituição Econômica, André Ramos Tavares (2011) explica que considerável parte da doutrina demonstra concordar que esta é fruto de considerável carga histórica, expressando valores consolidados no seio da sociedade.

Nesse sentido, concorda-se com Vicente Bagnoli (2017) ao entender que a Constituição Econômica integra o todo constitucional, não devendo haver qualquer rompimento à sua unidade 
por meio da interpretação de núcleos isolados, ainda que Constituição Federal de 1988 traga as disposições relativas à ordem econômica e social em títulos diversos, pois a Constituição Econômica está contextualizada nas disposições da Constituição Política. ${ }^{1}$

Tal fato decorre da exigência em se reconhecer que o Estado deve se ocupar de temas econômicos em sede constitucional, a fim de controlar positivamente os efeitos econômicos e atribuir segurança jurídica à matéria, e, assim, evitar crises como a da Quebra da Bolsa de Nova York em 1929. O Estado integra a Ordem Jurídica à Ordem Econômica, resultando na 'ordem Jurídico-Econômica' (BAGNOLI, 2017, p. 110).

Não obstante, a Constituição Econômica tem como conteúdo a previsão e delimitação dos direitos e responsabilidades daqueles que exercem a atividade econômica no mercado interno (TAVARES, 2011), razão esta que embasa seu papel norteador nas políticas de desenvolvimento e na atividade regulatória.

Embora inexista uma maneira totalmente eficiente de promover o desenvolvimento, é certo que compreender as razões do subdesenvolvimento é um importante passo para o aumento da eficiência econômica do país. Com isso, vale destacar que nem sempre as cláusulas constitucionais de vigilância do mercado são contrárias ao interesse dos agentes privados (TAVARES, 2017).

Destaca-se que o processo de desenvolvimento deve buscar suprir as diferentes falhas políticas e estruturais que atingem o país, o que irá refletir em um gradativo fortalecimento do mercado interno.

Para isso, a infraestrutura de transportes mostra-se como um elemento essencial na organização da economia moderna, demandando eficiência em suas operações por meio da integração dos modais, visando atender as necessidades do mercado globalizado, seja para a realização de atividades inerentes à distribuição interna de insumos e outros materiais, seja para realização de operações ligadas à exportação.

A Constituição Federal, em seu artigo 22, IX, atribui à União, privativamente, a competência para legislar sobre as diretrizes da política nacional de transportes. Já ao tratar da ordem econômica e financeira, no título VII, o referido diploma atribui à lei o dever de ordenar o transporte aéreo, aquático e terrestre (BRASIL, 1988). Diante disso, é possível notar a essencialidade desta infraestrutura para o desenvolvimento econômico do país.

No entanto, em razão de diferentes problemas que derivam de questões históricas e políticas, a infraestrutura de transportes brasileira está comprometida em seus diferentes modais, limitando sua eficiência se comparado a outros Estados ${ }^{2}$. Nessa linha, André Luiz dos Santos Nakamura (2019, p. 17) destaca que "o déficit de infraestrutura de transportes precisa ser

1 Vicente Bagnoli (2017) explica ainda que as constituições econômicas se consubstanciam em um conjunto de princípios e normas relativas à economia, previstas no seio de cada Carta. Segundo o autor, após a Constituição da República de Weimar, de 1919, diversos outros textos constitucionais passaram a incorporar em sua redação artigos, capítulos e títulos com teor econômico.

2 André Castro Carvalho (2014) destaca que inexiste um conceito jurídico comum de "infraestrutura" na doutrina nacional, mas que, em decorrência da dificuldade em conceituá-la, busca-se caracterizá-la por meio das peculiaridades que possui. 
urgentemente solucionado, sob pena de perpetrar a estagnação econômica e social no Brasil.”

Segundo André Ramos Tavares (2017), parte da condição de atraso vivenciada pelo Brasil se deve à precariedade da infraestrutura nacional. $\mathrm{O}$ referido autor explica que na eventual falência, ainda que parcial, de qualquer dos modais, surgiria a dependência de outros menos desenvolvidos, agravando os prejuízos ao mercado e à economia nacional.

Um dos principais problemas que recaem sobre a infraestrutura de transporte no país é a falta de estratégia de desenvolvimento, vez que grande parte dos investimentos realizados nos modais buscaram atender a necessidades momentâneas, havendo seu abandono quando do atingimento de seu propósito. ${ }^{3}$

A falta de estratégia de desenvolvimento da infraestrutura de transporte é responsável pela ausência de integração entre os modais, tornando-os poucos atrativos para a percepção de investimentos em decorrência do elevado risco, tanto para o Poder Público quanto para os agentes privados.

Durante toda a história do Brasil, não se verificou, salvo no ciclo do café e no período compreendido entre o Estado Novo de Getúlio Vargas e o regime militar, a realização de um investimento estatal relevante no desenvolvimento da infraestrutura de transportes. Especialmente após o final dos anos 70, o Estado deixou de priorizar o investimento, razão pela qual hoje existe um passivo enorme a ser superado (NAKAMURA, 2019, p. 23). ${ }^{4}$

A falta de investimento nos modais impacta consideravelmente na competitividade nacional em relação ao comércio exterior, o qual demanda eficiência e celeridade nas relações globalizadas.

Nessa linha, André Luiz dos Santos Nakamura (2019) destaca a importância da navegação neste novo cenário econômico, pois é necessária a existência de uma eficiente rede portuária para que se possa exportar a produção interna de maneira eficiência, aproveitando as benesses do livre comércio.

Observações também podem ser traçadas em relação a infraestrutura aeroportuária, a qual deve prover tanto o transporte de pessoas quanto de cargas (NAKAMURA, 2019). Para isso, é necessária a construção de novos aeroportos, voltados a atender a demanda de pequenos e médios centros, viabilizando o aumento do volume e da velocidade no transporte entre regiões estratégicas ou de difícil acesso.

No entanto, como já destacado, não basta simplesmente investir sem qualquer planejamento, por meio de uma simples política de infraestrutura. A eficiência desta está diretamente

3 "Em regra, não houve um planejamento que aproveitasse o potencial de cada modal de transporte, visando à construção de uma rede integrada. O maior investimento estatal verificado na história do transporte no Brasil, por razões políticas e em razão das características da nossa economia, ocorreu no modal rodoviário, com um abandono dos modais ferroviário e aquaviário" (NAKAMURA, 2019, p. 21).

4 "Na primeira metade do século XX, a percepção de que o Brasil ainda constituía um imenso arquipélago de ilhas econômicas traduziu-se na ideologia nacionalista da marcha para o Oeste e, nesta linha, os governos de Vargas e de Kubitschek consagraram a integração nacional como objetivo prioritário da política pública, por meio de grandes obras rodoviárias e da construção de Brasília. E, ainda recentemente, nos governos militares dos anos 60 e 70 , a integração do país vem a ser tratada como assunto de segurança nacional, sendo definitivamente consolidada" (GALVÃO, 1996, p. 184-185). 
ligada à maneira como os modais se integram, mas, para que isso ocorra de forma adequada, é imprescindível a elaboração de uma sólida estratégia nacional de desenvolvimento, voltada a atender interesses públicos definidos de forma prévia e clara.

Nessa linha, Roberto Mangabeira Unger (2017,p. 24) entende que a resolução do problema que recai sobre a infraestrutura nacional está condicionada à elaboração de uma estratégia nacional de desenvolvimento, pois, historicamente, o Brasil não teve uma, ou se teve, ela foi contraditória, ou houve contradição em relação à política de infraestrutura.

O regime militar promoveu grandes obras de infraestrutura no resto do País, naquilo que eu chamei a parte extensiva. Porém havia uma contradição: os militares nunca tiveram uma estratégia de desenvolvimento que não fosse a política de infraestrutura, mas a política de infraestrutura não é estratégia de desenvolvimento, ela cria condições, mas ela não preenche o espaço de uma estratégia (UNGER, 2017, p. 25).

Logo, é possível compreender que "a política de infraestrutura, mesmo quando alcança dimensão gigantesca, não produz o desenvolvimento por si só. No máximo, eleva o emprego e cria condições para uma estratégia desenvolvimento.” (UNGER, 2017, p. 26)

É importante destacar ainda que a infraestrutura, individualmente considerada, não é algo capaz de promover o pleno desenvolvimento do Estado, sendo, na verdade, um dos elementos que viabilizam tão condição, a qual está atrelada a diversos outros fatores, como a política de incentivos, regulação e tributação. Corroborando com tal entendimento, André Ramos Tavares (2017) defende, a partir da teoria econômica, que a infraestrutura se constitui em um pressuposto do desenvolvimento econômico, não devendo ser confundido com seu objetivo.

De fato, a experiência brasileira com as recomendações do Consenso de Washington na criação de uma nova estrutura institucional e jurídica, pautada no Direito estadunidense e nas recomendações das organizações multilaterais, falharam ao tentar promover maior confiança financeira e previsibilidade econômica, ensinando que "infraestrutura só se constrói no contexto de uma dinâmica de desenvolvimento" (UNGER, 2017, p. 25).

Se por um lado é constitucionalmente inadmissível e insustentável uma política econômica voltada a reduzir a infraestrutura ou a criar empecilhos jurídicos e econômicos para o seu desenvolvimento (TAVARES, 2017, p. 43), por outro, tem-se o Estado incapaz de investir em infraestrutura por falta de recursos, imaginando ser suficiente o arcabouço jurídico e institucional para justificar o investimento privado, o que não ocorre em grande escala (UNGER, 2017, p. 27).

Destarte, torna-se visível o papel da infraestrutura para a economia moderna, consubstanciando-se em um importante instrumento para o desenvolvimento do Estado, notadamente em um cenário de integração econômica internacional, o qual requer uma ampla e eficiente estratégia de desenvolvimento, sob pena de perpetrar a estagnação comercial do país. 


\section{REESTRUTURAÇÃO, INTEGRAÇÃO E FINANCIAMENTO}

Conforme explicado, a infraestrutura possui um caráter instrumental para o desenvolvimento do Estado, razão esta que embasa diversos estudos sobre o tema. Discute-se, também, o papel do Estado na realização de investimentos neste setor, com correntes que adotam posicionamentos bastante distintos.

As possibilidades de promoção de infraestrutura pelos Estados não é consensual entre as diferentes teorias econômicas. Os economistas clássicos e neoclássicos propõem uma separação mais sensível entre o Estado e o mercado. Teorias econômicas neoclássicas mais ortodoxas, como a de Adam Smith, em A riqueza das nações, sustentam que as funções básicas do Estado devem restringir-se à defesa, ao direito como regulador de alguns fatos sociais, como a propriedade privada, a estrutura da competição e da cooperação e, por fim, a ordem. As teorias estruturalistas, as quais defendem uma atuação mais extensiva do Estado na economia, defendem que as funções do Estado extrapolam a capacidade de determinação e garantia do sistema jurídico, devendo também criar condições materiais de produção, mais comumente conhecida como a infraestrutura, além de garantir a mediação entre salário e capital (ARAGÃO, 2017, p. 30, grifo do autor).

No entanto, é certo que a infraestrutura brasileira carece de investimento e de integração, o que contribui para a sua obsolescência. Assim, entende-se ser imperiosa a elaboração de uma estratégia nacional de desenvolvimento que verse sobre a reestruturação física, técnica e regulatória dos modais no país.

Para Roberto Mangabeira Unger (2017), atualmente o imperativo nacional é a elaboração de uma nova estratégia de desenvolvimento, substancialmente diversa daquela adotada na história do país.

Nakamura (2019) chama a atenção para o período de decadência que recaiu sobre o modal ferroviário após sua expansão, pois assim como os demais modais, ela não foi devidamente planejada, inexistindo qualquer previsão realmente eficiente sobre sua manutenção, conversação e expansão. ${ }^{5}$

Com o advento da expansão do modal rodoviário, as ferrovias foram gradativamente abandonadas, pois as rodovias não foram projetadas para complementar o sistema ferroviário, mas sim, para substituí-lo (NAKAMURA, 2019).

Embora o modal rodoviário seja o mais desenvolvido do país, o The Global Competitiveness Report 2019 traz que, em termos de qualidade, o Brasil guarda a $116^{\text {a }}$ posição. Logo, o modal rodoviário nacional está longe de fazer frente às rodovias de países como Portugal $\left(8^{\circ}\right)$, China $\left(45^{\circ}\right)$ e Uruguai $\left(86^{\circ}\right.$ ) (WORLD ECONOMIC FORUM, 2019).

Por outro lado, o sistema ferroviário passou a atender apenas o transporte de cargas,

5 “Os traçados das linhas não eram feitos por critérios técnicos, mas políticos, visando à valorização de propriedades lindeiras às ferrovias; não houve uma padronização de bitolas, o que inviabilizou qualquer tentativa de integração entre as malhas ferroviárias" (NAKAMURA, 2019, p. 24). 
conforme os interesses dos concessionários das linhas remanescentes, inexistindo qualquer serviço de transporte de passageiros à longa distância neste modal no país (NAKAMURA, 2019).

Problemas podem ser encontrados na maneira como as concessões das linhas férreas foram realizadas, pois não consideraram o sistema de forma global, inexistindo qualquer regulação que buscasse garantir a interligação do sistema ${ }^{6}$, o que pode ser notado com a criação da Agência Nacional de Transportes Terrestres (ANTT), que ocorreu mais de cinco anos após o término das concessões do setor (NAKAMURA, 2019).

Entretanto, para tentar solucionar parte dos problemas incidentes nas concessões ferroviárias, seria necessário revê-las, além de realizar fortes investimentos na interligação do sistema, haja vista os problemas técnicos que recaem sobre o mesmo, visando, com isso, reduzir a sobrecarga dos demais modais e aliviar o caos logístico e de mobilidade que se vivencia no país (NAKAMURA, 2019). ${ }^{7}$

O Fórum Econômico Mundial (SCHWAB, 2019), traz dados importantes sobre este modal no país, merecendo destaque a $86^{\text {a }}$ posição em relação à eficiência dos serviços ferroviários, atrás de países como a Alemanha $\left(16^{\circ}\right)$ e México $\left(58^{\circ}\right)$.

A integração do transporte aquaviário também se mostra de suma importância, em especial, para ligar regiões mais remotas, facilitando o transporte de pessoas e cargas pelo interior do país.

Embora a formação de uma infraestrutura hidroviária eficiente demande elevados investimentos, se comparada à infraestrutura rodoviária, é inegável sua superioridade no volume de cargas transportadas em uma única viagem, além de causar menores danos ao meio ambiente. No entanto, a falta de investimento no setor, levou a infraestrutura portuária nacional ao sucateamento, sendo o modal mais precário no país. (NAKAMURA, 2019)

Em relação a infraestrutura hidroviária, merece destaque a concentração com a qual a estrutura portuária atende as demandas nacionais, gerando gargalos logísticos e demandando maior eficiência. ${ }^{8}$

Para o estado de São Paulo, especificamente, observamos que quase $90 \%$ do valor de todas as cargas movimentadas por esse estado correspondem a movimentações pelo porto de Santos. Para o estado de Alagoas, o porto de Maceió é responsável por $85 \%$ a $90 \%$ do valor total movimentado, ao longo dos quinze anos da amostra. Para o Espírito Santo, o porto de Vitória tem mais de $90 \%$ de participação em quase todo o intervalo estudado. Para o estado do Paraná, a participação do porto de Paranaguá não chega a $80 \%$, mas flutua em torno de $75 \%$, quando consideramos todas as cargas, ou entre $75 \%$ e $80 \%$, quando levamos em conta especificamente

6 André Castro Carvalho (2014) explica a importância da homogeneidade para a eficiência da infraestrutura, vez que está diretamente relacionada à padronização técnica. Seria o caso, por exemplo, dos standards para as bitolas das linhas férreas

7 “A decadência do setor ferroviário e portuário, em razão da crise dos anos 30, contribuiu para que as rodovias e estradas superassem em importância e em volume os transportes realizados por trens e navios, que dependiam muito do setor exportador. No Brasil, $65 \%$ da produção é deslocada em caminhões; $20 \%$ por trens; $12 \%$ pelo transporte aquaviário; $3 \%$ pelo dutoviário; e $0,1 \%$ pelo aéreo. Não somente no setor de transportes de mercadorias o modal rodoviário é o protagonista. Na movimentação de passageiros, o predomínio ainda é maior, sendo que $90 \%$ do transporte de pessoas se dá por coletivos rodoviários ou veículos individuais" (NAKAMURA, 2019, p. 30-31).

8 Destaca-se que o Brasil, em termos de eficiência dos serviços portuários, está atrás de países como Singapura $\left(1^{\circ}\right)$, China $\left(52^{\circ}\right)$ e Argentina $\left(81^{\circ}\right)$, guardando a $104^{\mathrm{a}}$ posição (SCHAB, 2019). 
contêineres (CARVALHO et al., 2015, p. 19).

No tocante à infraestrutura aeroportuária, Nakamura (2019, p. 42) explica que esta não compete com as demais, pois o transporte rodoviário atende um número maior de cidades, bem como, inexistem ferrovias que atendam os mesmos trechos que as aeronaves. Além disso, o autor destaca que, em razão do elevado custo operacional, o transporte de cargas por via aérea compreende menos de $1 \%$ do volume transportado do país. ${ }^{9}$

Com isso, pode-se perceber a precariedade do transporte no Brasil, o qual demanda uma profunda mudança em sua estrutura, viabilizando a integração dos modais, e, assim, criando meios para o desenvolvimento a partir de uma infraestrutura eficiente.

A competitividade do país em relação ao mercado internacional está diretamente atrelada à eficiência com a qual o mercado interno consegue atender a estas demandas, pois como bem discorre Marcos Nóbrega (2011, p. 24), "não há crescimento econômico sustentável sem condições adequadas de infraestrutura".

Logo, a infraestrutura de transportes se mostra um setor sensível ao crescimento econômico nacional, demandando investimentos para seu pleno desenvolvimento, em especial, caso se busque fazer frente a países emergentes como a Índia, China e Rússia (NÓBREGA, 2011).

Embora os recursos sejam escassos e o planejamento de reestruturação da infraestrutura de transporte seja complexo, deve-se buscar a criação de um modelo neutro, que não vise beneficiar um modal em detrimento dos demais (UNGER, 2017), de modo a servir à iniciativa privada sem condicionar a atividade econômica, visando, com isso, permitir aos agentes econômicos atender as demandas do mercado conforme sua estratégia de negócios.

Roberto Mangabeira Unger (2017, p. 28) entende que a infraestrutura não deve ser constituída para atender apenas às grandes empresas da mineração ou do agronegócio, mas sim, para suprir a demanda dos empreendimentos emergentes brasileiros. Deste modo, "[...] ela precisa estar em todo lugar, ela precisa ter um cunho multimodal, ela precisa avançar dentro do território".

Busca-se, com isso, fortalecer o mercado interno, na tentativa de romper com a dependência externa, não por meio do isolamento econômico, mas pela participação no mercado internacional de forma competitiva e igualitária, para que se possa, então, assegurar a soberania econômica nacional (art. 170, I, CF) (GRAU, 2015).

André Ramos Tavares (2011) destaca que atualmente inexiste um Estado amplamente soberano, principalmente se o fator econômico for entendido como uma de suas expressões, haja vista o processo de globalização ter gerado imensa dificuldade em promover o desenvolvimento de uma economia nacional de forma independente a outros sistemas econômicos internacionais.

Unger (2017) explica ainda a necessidade de adensar a infraestrutura de transportes dentro do país, fazendo-se presente localmente e servindo às políticas regionais, pois a estratégia nacional de desenvolvimento só será efetiva se compreender as reais necessidades do Brasil.

Almeja-se, assim, evitar o surgimento de grandes vazios de logística, isolando economias

9 Em relação a este modal, o The Global Competitiveness Report 2019 classifica o Brasil na $85^{a}$ posição em relação à eficiência dos serviços aeroportuários, atrás de países como Uruguai $\left(41^{\circ}\right)$, Chile $\left(54^{\circ}\right)$ e Argentina $\left(83^{\circ}\right)(\mathrm{SCHWAB}$, 2019). 
regionais ${ }^{10}$. Para tanto, faz-se importante uma considerável dinâmica de investimento público, sem o qual não é possível se falar em infraestrutura (UNGER, 2017).

Pode-se perceber, então, que sem uma correta integração da infraestrutura de transportes, de nada adiantará tentar reestruturar os modais no país. Ademais, a reordenação da infraestrutura de transportes deve obedecer a lógica da estratégia nacional de desenvolvimento, a qual seria responsável por delimitar os objetivos do Estado ao longo dos anos seguintes.

Emborabusque-se evidenciara importância de uma estratégia nacional de desenvolvimento, ao invés da adoção de uma simples política nacional de expansão da infraestrutura de transportes, cabe lembrar que o Brasil conta com diferentes instrumentos normativos que regem o Sistema Nacional de Viação.

Merece destaque a Lei $n^{\circ} 10.233 / 01$, que dispõe, dentre outras coisas, sobre a criação do Conselho Nacional de Integração de Políticas de Transporte - CONIT. Este Conselho, tinha como atribuição "[...] propor ao Presidente da República políticas nacionais de integração dos diferentes modos de transporte de pessoas e bens [...]", as quais deveriam estar em conformidade, entre outros, “[...] com as políticas de desenvolvimento nacional, regional e urbano [...]", tal qual dispõe o art. $5^{\circ}$, I. (BRASIL, 2001, art. 5).

Importante salientar que o artigo $5^{\circ}$ e seguintes, que tratavam do CONIT, foram revogados em 2019, por meio da Lei $\mathrm{n}^{\mathrm{o}}$ 13.844. Com isso, atribuiu-se ao Ministério da Infraestrutura a competência para tratar da "política nacional de transportes ferroviário, rodoviário, aquaviário, aeroportuário e aeroviário", bem como sua participação no planejamento estratégico e na definição de prioridades dos programas de investimentos em transportes (art. 35, I e VI da Lei n ${ }^{0}$ 13.844/19, respectivamente), além de outros temas de significativa importância para o setor (BRASIL, 2019).

A referida norma adota a integração nacional como um dos objetivos essenciais do Sistema Nacional de Viação (art. $4^{\circ}$, III, Lei no 10.233/01). Sobre ele, pode-se dizer que ao prever tal disposição, “[...] a União direcionou a atuação do Estado e de todos os entes federados, como também dos agentes privados concedidos, rumo ao desenvolvimento de uma infraestrutura viária integrada" (TAVARES, 2017, p. 57, grifo do autor).

Como descrito, todo o processo de reestruturação dos modais demandará um significativo investimento público, cujo Estado nem sempre estará disposto ou poderá realizar. Logo, a participação de capital privado se torna uma opção para o financiamento de tal empreendimento.

O investimento privado não recairá sobre o projeto de infraestrutura de maneira espontânea, o que forçará o Estado a buscar meios de despertar o interesse privado para a realização deste dispêndio, notadamente pelo risco que a atividade possui.

Embora a concessão em regime de monopólio tenha sido utilizada ao longo da história nacional como instrumento de incentivo à expansão do modal ferroviário, não se tem esse tipo de política como algo eficiente, vez que o monopólio tende a apresentar-se como uma falha do mercado, limitando o desenvolvimento do setor.

10 "Por exemplo, uma ferrovia norte e sul dentro de uma realidade em que não há qualquer plano para poder atravessar de oeste a leste a Ilha do Bananal, e esses exemplos poderiam se multiplicar às dezenas.” (UNGER, 2017, p. 28). 
Nesse contexto, as Parcerias Público-Privadas - PPP, emergem como uma alternativa à medida em que pulverizam o risco do empreendimento entre os agentes que dela participam. Como bem explica Vicente Bagnoli (2017, p. 190), estes contratos administrativos possuem interesse geral e de caráter continuado, vinculando o Estado e os agentes econômicos privados, de modo a propiciar o tão almejado desenvolvimento socioeconômico.

Não se trata de uma invenção nacional. As PPPs são utilizadas nos Estados Unidos da América como arranjos realizados entre o Estado e empresas privadas ou organizações sem fins lucrativos, em que se estabelecem funções e tarefas que cada um deverá desempenhar. Em países da Europa, no contexto da crise do welfare state, as PPPs despontam como alternativa, ou até mesmo necessidade, para arranjos conjunturais e estruturais (BAGNOLI, 2017, p. 200-201, grifo do autor).

A utilização da PPP como instrumento de financiamento dos projetos públicos mostra-se vantajosa em diversas frentes, gerando benesses para: "[...] o Estado, com ganhos econômicos, sociais e até políticos; as empresas, com a aferição de lucros; e, sobretudo, a coletividade, com o serviço que está sendo prestado" (BAGNOLI, 2017, p. 200).

Destaca-se, ainda, que no ano de 2016, o Brasil instituiu uma nova maneira de tentar angariar parceiros privados para a realização de obras tidas como estratégicas no setor de transportes, criando-se, assim, o chamado Programa de Parcerias de Investimentos - PPI, que será abordado em capítulo próprio.

Contudo, reitera-se que a reestruturação dos modais no Brasil depende, primeiramente, da elaboração de uma estratégia nacional de desenvolvimento, para que se possa, então, realizar uma eficiente articulação entre Poder Público e a iniciativa privada na captação de recursos para este projeto.

\section{REGULAÇÃO DOS MODAIS NO BRASIL}

A história econômica demonstrou que o mercado necessita da presença do Estado, enquanto agente regulador, para que se possa exercer, com um mínimo de plenitude, o direito à livre iniciativa e à livre concorrência, sem que os novos agentes tenham seu espaço suprimido pela prática de abusos do poder econômico. Como explica Eros Grau (2015), o mercado não pode ser regido por suas próprias regras, sob pena de criar males permanentes.

Com isso, embora o Direito e a Economia tenham propósitos, por vezes, conflitantes, não se pode afastá-los sob o pretexto de promover o desenvolvimento, devendo, o Estado, exercer seu papel fiscalizador sem desequilibrar o fluxo das relações privadas. Nessa linha, Alexandre Santos de Aragão (2017) traz que o mercado, para sobreviver como instituição, depende da proteção externa, a qual é exercida pelo Direito.

Assim, a regulação se apresenta como um importante instrumento de controle da atividade econômica na medida em que impede a exploração das falhas de mercado e o direciona rumo ao 
atendimento dos objetivos desenvolvimentistas do Estado.

A atividade regulatória é tida como uma das diferentes modalidades de intervenção do Estado na economia, razão esta que resulta em diversas discussões quanto a extensão teórica e prática deste instituto. Nessa linha, Floriano de Azevedo Marques Neto (2019) explica que a atividade regulatória enseja debates relativos à participação do Estado na economia e na sociedade, tratandose de uma antiga pauta que questiona posicionamentos políticos e ideológicos.

Aragão (2017, p. 32-33) explica que o verbo "intervir" denota a ideia de atuação em algo alheio, o que não seria tecnicamente correto, pois o mercado só existe e se desenvolve a partir do Direito e do Estado, cabendo, inclusive, a este, tratar de matérias econômicas. Com isso, o autor defende o uso do termo "atuação" em relação ao papel do Estado na economia.

Assim, a atuação do Estado ocorre de duas maneiras, direta e indireta. A atuação direta é aquela em que o Estado age na economia, exercendo a atividade econômica, tanto por meio de monopólio quanto em regime de concorrência com os agentes privados. Já na atuação indireta, o Estado age sobre a economia, regulando o mercado por meio de normas destinadas aos agentes privados, induzindo ou inibindo comportamentos destinadas aos agentes privados. (ARAGÃO, 2017)

Por outro lado, Eros Grau (2015, p. 90-91) defende que "atuação estatal” possui um significado demasiado amplo, podendo conotar, inclusive, atuação do Estado na esfera pública, quando não devidamente qualificada.

Vicente Bagnoli (2017), por sua vez, explica que o Estado pode intervir no domínio econômico por absorção ou participação. Por absorção, quando controla em regime de monopólio os meios de produção de determinado setor. Por outro lado, a intervenção por participação é aquela que ocorre quando o Estado age em condição de concorrência com os agentes privados. Logo, quando ele intervém no domínio econômico, age como agente econômico.

Já a intervenção sobre o domínio econômico se dá por direção ou por indução. Por direção, quando o Estado estabelece o comportamento dos agentes econômicos. A intervenção por indução ocorre quando o Estado manipula o funcionamento do mercado através da lei (BAGNOLI, 2017).

Contudo, fundado na competência do Estado em regular o mercado, entende-se que este não é algo alheio àquele, no entanto, a atividade econômica propriamente considerada, desenvolvida dentro dos limites impostos pelo Estado regulador, é de competência privada, razão esta que o torna intervencionista quando age nesta seara ${ }^{11}$.

De qualquer modo, busca-se aqui tratar propriamente da regulação, ou seja, da maneira como o Estado limita a atuação dos agentes privados no mercado interno. Floriano de Azevedo Marques Neto (2019) explica que a regulação não ocorre a partir de comandos binários permissivos ou proibitivos, mas, sim, com base no atingimento dos objetivos públicos, em concerto com os agentes sociais e econômicos.

11 De qualquer modo, frente a usualidade do termo "intervenção", passa-se a adotá-lo para tratar da participação direta e indireta do Estado na economia. 
Ao longo das últimas décadas, a concepção ideal de atuação do Estado na economia sofreu diversas mudanças no Brasil, onde, até meados de 1970, acreditava-se que o desenvolvimento nacional seria atingido diretamente pelo Estado, através de suas entidades administrativas, excluindo determinados setores da esfera privada por se tratarem de monopólios estatais ou serviços públicos (MARQUES NETO, 2019). Ou seja, o modelo de atuação direta (Estado prestador) era predominante na economia brasileira.

Nessa mesma época pode-se observar o surgimento das empresas públicas que tentaram salvaguardar o setor ferroviário por meio da estatização. Na esfera federal havia a Rede Ferroviária Federal S.A. - RFFSA, criada em 1957; e na esfera estadual, a Ferrovia Paulista S.A. - FEPASA, instituída em 1971.

Já a partir da década de 1980, a concepção ideal de atuação do Estado na economia passou a seguir o modelo indireto, pautado na regulação propriamente dita. O Estado Regulador não foi apenas uma tendência nacional, mas fruto de amplos debates internacionais buscando disciplinar os mercados liberalizados. No entanto, a noção de Estado Regular varia conforme o país, tratando-se de um conceito polissêmico. Diferente dos debates norte-americano e europeu, voltados à superação do Estado do Bem-Estar Social, o modelo de Estado Regulador brasileiro se deu no âmbito da Reforma do Estado, na década de 1990, associada ao processo público de tomada de decisão e às novas categorias operacionais a serem introduzidas no país (MARQUES NETO, 2019).

Bresser Pereira (2006, p. 24) dispõe que a reforma do Estado, em virtude de sua complexidade, envolve aspectos politicos, econômicos e administrativos. Mais do que isso, percebeu-se que o modelo de gestão pública utilizada até então não correspondia mais aos interesses socias. Assim, mudanças foram necessárias para reduzir a lacuna que separa a demanda social e a satisfação dessa demanda."

Explica Irene Nohara (2012), o Plano Diretor de Reforma do Aparelho do Estado questionou a atuação direta do Estado no domínio econômico, destacando também o interesse político em transferir para o setor público não estatal a execução de atividades que não dependiam necessariamente da atuação do Poder Público, com sua atuação se limitando a subsidia-las.

A referida autora traz ainda que o Plano Diretor de Reforma do Aparelho do Estado buscou romper com o modelo burocrático visto até então, tendo enfoque nos resultados e não mais nos processos, iniciando a fase gerencial da Administração Pública brasileira (NOHARA, 2012).

Com o advento do novo modelo institucional, pautado na regulação através das Agências Reguladoras, o país passou por um processo de privatização, no qual apenas parte das empresas públicas foi desestatizado - abrindo novos mercados, sem que houvesse desregulação, a fim de assegurar a satisfação dos valores públicos pelos particulares -, e sem retirar do Poder Público sua competência administrativa (MARQUES NETO, 2019).

No que se refere a estrutura regulatória dos modais, como destacado, cabe mencionar a criação da Agência Nacional de Transportes Terrestres - ANTT, instituída pela Lei 10.233/01, a qual também criou a Agência Nacional de Transportes Aquaviários - ANTAQ. 
André Ramos Tavares (2017) destaca que a Lei $\mathrm{n}^{\circ}$ 10.233/01, ao prever em seu art. 22 as competências da ANTT, limitou sua atuação em relação ao transporte rodoviário de passageiros à esfera interestadual e internacional (inc. III), enquanto, ao transporte de bens, concede atuação mais ampla, tratando do transporte rodoviário de cargas regulares, especiais e perigosas (inc. IV e VII), além das cargas perigosas transportadas por ferrovias (inc. VII).

Embora atualmente a ANTAQ detenha em sua esfera de atuação questões relacionadas a navegação, como: a porto organizado, o transporte de cargas e a exploração da infraestrutura aquaviária federal (art. 23, II, IV e V da Lei $n^{\circ} 10.233 / 01$, respectivamente), a mesma não foi a primeira entidade voltada à regulação deste modal no país.

As primeiras instituições relacionadas ao transporte aquaviário são a Inspetoria Federal dos Portos, Rios e Canais e a Inspetoria Federal de Navegação vinculadas ao Ministério da Viação e Obras Públicas, criadas em 1911. Em 1932 é criado o Departamento Nacional de Portos e Navegação (DNPN) cuja competência era zelar pela infraestrutura da navegação. Este, em 1943, é substituído pelo Departamento Nacional de Portos, Rios e Canais (DNPRC). No ano de 1963 é criado o Departamento Nacional de Portos e Rios Navegáveis (DNPVN). Por fim, em 1975 é criada a Empresa de Portos do Brasil (Portobrás) que foi extinta em 1990, gerando um grande prejuízo ao setor (NAKAMURA, 2019, p. 36-37).

Ainda que as medidas de concessão dos portos e hidrovias brasileiras tenham sido iniciadas ainda em 1993, a ANTAQ, como mencionado, foi criada juntamente com a ANTT, em 2011, impedindo a elaboração de qualquer estratégia de integração e desenvolvimento do setor, transparecendo a falta de planejamento no programa de concessões (NAKAMURA, 2019).

Até o advento da Lei $\mathrm{n}^{\circ} 12.815 / 13$, a atividade portuária era regida por diferentes diplomas normativos. Essa mudança teve como principal motivação "[...] o plano de privatizações que dominou o Brasil nessa década e que passou a dar outro formato para os serviços públicos, especialmente o portuário" (JESUS, 2018, p. 27).

A infraestrutura aeroportuária, por sua vez, tem sido regulada pelo Poder Público desde 1931. Primeiramente, pelo Departamento de Aeronáutica Civil - DAC, instituída pelo Dec. $\mathrm{n}^{\circ}$ 19.902/31, passando, em 1941, à competência do Ministério da Aeronáutica, que, até 1986, absorveu a DAC e as aviações militares, quando os serviços aeroportuários foram divididos em público e privado, em decorrência da promulgação do Código Brasileiro de Aeronáutica - CBA (Lei $\mathrm{n}^{\mathrm{o}}$ 7.565, de 19.12.1986) (NAKAMURA, 2019).

Por meio da Lei 5.862, de 12.12.1972, foi autorizada a criação da Empresa Brasileira de Infraestrutura Aeroportuária - INFRAERO, empresa pública que tinha por finalidade implantar, administrar, operar e explorar industrial e comercialmente a infraestrutura aeroportuária. A Infraero conseguiu, ao longo dos anos, manter um bom nível de investimentos, apesar dos períodos de crise dos anos 80 e 90. A lei 11,182, de 27.09.2005, instituiu a Agenda Nacional de Aviação Civil (Anac) (NAKAMURA, 2019, p. 41). ${ }^{12}$

12 A concessão dos aeroportos nacionais começou em 2011, seguindo o modelo de Estado regulador, conforme 
Todas essas mudanças podem, de certo modo, comprometer o desempenho operacional dos modais no país, vez que acaba por burocratizar a formação de um plano geral de gestão do sistema, especialmente ao considerar que a eficiência do sistema se dá em virtude da atuação em rede.

Ante o exposto, é possível compreender o caos regulatório que, há décadas, assola os principais modais de transporte brasileiros, razão essa que fundamenta uma reorganização da política de expansão e regulação da infraestrutura no país, pautada em um sólido e transparente plano de desenvolvimento nacional, capaz de se sobrepor a qualquer ideologia política em prol do Brasil, tornando a logística interna mais eficiente e ampliando o potencial participativo no mercado internacional.

Há poucos anos, o Brasil, visando incentivar a reestruturação e integração dos modais, instituiu um novo modelo de parceria entre o Poder Público e a iniciativa privada, buscando reduzir questões burocráticas e tornar mais célere a concretização deste projeto.

\section{DESENVOLVIMENTO E O PROGRAMA DE PARCERIAS DE INVESTIMENTOS - PPI}

Frente a problemas como os apontados, o Estado brasileiro, no ano de 2016, publicou a Lei ${ }^{\circ}$ 13.334, fruto da conversão da Medida Provisória 727, do mesmo ano, criando o Programa de Parcerias de Investimentos - PPI.

Como versa a exposição de motivos da referida MP, tal programa busca ampliar e fortalecer a integração entre o Poder Público e a iniciativa privada, a fim de viabilizar a infraestrutura nacional, a qual tem sua importância reconhecida como algo fundamental à retomada do crescimento econômico (BRASIL, 2016).

Mais do que isso, a referida norma tem por objetivo, dentre outros, ampliar as oportunidades de investimentos; expandir a infraestrutura pública com qualidade; fortalecer a função reguladora do Estado; e, fortalecer as políticas de integração dos modais de transporte, sejam eles de bens ou de pessoas (art. $2^{\circ}$, I, II, V, VI da Lei n ${ }^{\circ} 13.334 / 16$, respectivamente) (BRASIL, 2016).

Para isso, foram estabelecidos princípios balizadores para a implementação do Programa de Parcerias de Investimentos, cabendo menção a dois: a estabilidade das políticas públicas de infraestrutura e a garantia de segurança jurídica aos agentes públicos, às entidades estatais e aos particulares envolvidos (art. $3^{\circ}$, I e III da Lei no 13.334/16, respectivamente) (BRASIL, 2016).

Entende-se que o princípio da estabilidade das políticas públicas de infraestrutura tem o condão de assegurar a previsibilidade das ações normativas e regulatórias, o que resulta no princípio seguinte, a segurança jurídica aos agentes públicos, às entidades estatais e aos particulares envolvidos nos contratos de PPI.

A previsibilidade quanto às regras do mercado é essencial para a avaliação dos riscos e para a tomada das decisões por parte do parceiro privado, permitindo, assim, a definição de estratégias em relação às variáveis econômicas de determinado mercado. (FURTADO, 2013)

predomina no Brasil. A fim de assegurar a participação do Poder Público na gestão dos aeroportos concedidos, a Infraero manteve $49 \%$ por cento de participação no consórcio das empresas vencedoras (NAKAMURA, 2019). 
Segundo o artigo $1^{\mathrm{o}}$ da Lei $\mathrm{n}^{\mathrm{o}} 13.334 / 16$, este processo de integração entre o Estado e a iniciativa privada ocorrerá através de contratos firmados “[...] para a execução de empreendimentos públicos de infraestrutura e de outras medidas de desestatização" (BRASIL, 2016, art. 1).

Não se pode negar que a busca pela desestatização é reflexo do modelo regulatório anteriormente abordado, expressando e ratificando o papel de agente regulador do Estado brasileiro. Contudo, a norma supramencionada prevê, em seu art. $1^{\circ}, \S 1^{\circ}$, que apenas quatro tipos de empreendimentos podem ser objeto das PPI's ${ }^{13}$ (BRASIL, 2016).

$\mathrm{O}$ art. $5^{\circ}$ da Lei $\mathrm{n}^{\mathrm{o}} 13.334 / 16$ textualiza a importância que a infraestrutura possui dentro do Programa de Parcerias de Investimentos, à medida em que qualifica seus projetos como empreendimentos de interesse estratégico, atribuindo-lhes caráter prioritário nacional para todos os agentes públicos da esfera administrativa e controladora da Administração Pública Direta (BRASIL, 2016).

É importante destacar ainda a criação do Conselho do Programa de Parcerias de Investimentos - CPPI, o qual possui, dentre outras competências, a de propor medidas visando a integração dos modais aéreo, aquaviário e terrestre (aqui entendido o rodoviário e ferroviário), bem como a harmonização das políticas setoriais (Art. $7^{\circ}$, VII da Lei $n^{\circ}$ 13.334/16) (BRASIL, 2016).

Outra importante competência do Conselho é a harmonização das políticas de transporte dos Estados, Distrito Federal e Municípios em relação às políticas nacionais de transporte (Art. $7^{\circ}$, IX da Lei $\left.n^{\circ} 13.334 / 16\right)$.

Com base no que foi apresentado, entende-se que ambas as competências são uma resposta ao problema de integração, horizontal e verticalmente, pois busca-se integrar os modais na esfera federal, de modo a também harmonizar este processo à infraestrutura dos modais a nível estadual e municipal.

No entanto, esta não é uma tarefa simples, pois demanda uma perfeita articulação entre os entes federativos. Mas para isso, reitera-se a necessidade da criação de um sólido plano de desenvolvimento nacional, de maneira a otimizar o gasto com os recursos públicos e privados objeto da parceira, além de melhor definir as carências do transporte regional e os resultados dos investimentos no setor.

A Lei $n^{\circ}$ 13.334/16 também autorizou o Banco Nacional do Desenvolvimento - BNDES a constituir e participar do Fundo de Apoio à Estruturação de Parcerias - FAEP, que, por meio de contrato, visará a prestação onerosa de serviços técnicos profissionais especializados, tanto para a estruturação de parcerias de investimento quanto para medidas de desestatização (art. 14) (BRASIL, 2016).

13 “[...] $\S 1^{\circ}$ Podem integrar o PPI: I - os empreendimentos públicos de infraestrutura em execução ou a serem executados por meio de contratos de parceria celebrados pela administração pública direta e indireta da União; II os empreendimentos públicos de infraestrutura que, por delegação ou com o fomento da União, sejam executados por meio de contratos de parceria celebrados pela administração pública direta ou indireta dos Estados, do Distrito Federal ou dos Municípios; e III - as demais medidas do Programa Nacional de Desestatização a que se refere a Lei $\mathrm{n}^{\circ}$ 9.491, de 9 de setembro de 1997; e (Redação dada pela Lei no 13.901, de 2019) IV - as obras e os serviços de engenharia de interesse estratégico. (Incluído pela Lei no 13.901, de 2019) [...]"(BRASIL, 2016, art.1). 
O FAEP possui natureza privada e patrimônio próprio, podendo celebrar em seu nome contratos, acordos e qualquer ajuste necessário à realização de sua atividade, tendo prazo inicial de dez anos, prorrogável por igual período, cabendo ao BNDES sua administração e representação judicial e extrajudicial (art. 14, $\S 1^{\mathrm{o}}, \S 2^{\mathrm{o}}, \S 4^{\circ}$ da Lei $\mathrm{n}^{\mathrm{o}}$ 13.334/16) (BRASIL, 2016).

Cabe destacar ainda que o Programa de Parcerias de Investimentos será regulado através de decreto que definirá, entre outras coisas, as obras e os serviços de engenharia que possuem interesse estratégico (art. $4^{\circ}$, IV da Lei $\mathrm{n}^{\circ}$ 13.334/16), respeitados os limites das leis setoriais e da normatização geral aplicável (BRASIL, 2016).

Embora a Lei $\mathrm{n}^{\mathrm{o}}$ 13.334/16 tenha inovado no sistema jurídico brasileiro instituindo as características gerais do Programa de Parcerias de Investimentos, foi Lei $n^{\circ} 13.448 / 17$ que, por meio da definição de novos instrumentos, buscou auxiliar o referido programa no processo de desburocratização das parcerias entre o Poder Público e a iniciativa privada. Trata-se da prorrogação e relicitação dos contratos de parceria.

Tais institutos são aplicáveis apenas aos setores rodoviário, ferroviário e aeroportuário (art. $1^{\circ}$ ), desde que estes empreendimentos públicos tenham sido previa e especificamente qualificados para integrar o Programa de Parcerias de Investimentos (art. $2^{\circ}$, Lei n $\left.{ }^{\circ} 13.448 / 17\right)$ (BRASIL, 2017).

$\mathrm{O}$ artigo $3^{\circ}$ da Lei $n^{\circ} 13.448 / 17$ expressa a importância do emprego das melhores práticas regulatórias e da incorporação tecnológica quando da celebração do contrato de prorrogação e relicitação pelo Ministério ou Agência Reguladora competente (BRASIL, 2017).

Tratando dos novos instrumentos, a referida lei, ao versar sobre a prorrogação contratual da parceira, dispõe que esta deve estar prevista expressamente no edital ou no contrato original, a qual fica a critério da entidade competente e de comum acordo com o contratado; no mais, o contrato de prorrogação antecipada segue a mesma linha do anterior, mas produz efeitos antes do termo final de vigência do ajuste; e a relicitação que consiste na extinção amigável do contrato de parceria e o firmamento de um novo ajuste negocial para o mesmo empreendimento, possuindo novas condições e novos parceiros privados, através de licitação para este fim $\left(\operatorname{art.~4^{\circ }}\right.$, Lei $n^{\circ}$ 13.448/17) (BRASIL, 2017).

A relicitação ocorre quando as disposições contratuais de determinada licitação não estiverem sendo atendidas ou havendo incapacidade do parceiro privado em adimplir as obrigações contratuais ou financeiras firmadas, buscando-se, assim, garantir a continuidade da prestação dos serviços (art. 13 ${ }^{\circ}$ Lei n ${ }^{\circ}$ 13.448/17) (BRASIL, 2017).

Contudo, a relicitação se dará de maneira não litigiosa, por meio de acordo entre as partes envolvidas, atendendo aos termos e prazos fixados em ato do Poder Executivo. No mais, é de competência da entidade responsável pelo contrato de parceria firmado o dever de avaliar a necessidade, a permanência e a razoabilidade quanto à instauração do processo de relicitação (art. $14^{\mathrm{o}}, \S 1^{\mathrm{o}}, \S 2^{\mathrm{o}}$, Lei $\left.\mathrm{n}^{\mathrm{o}} 13.448 / 17\right)$ (BRASIL, 2017).

Ambos os instrumentos (prorrogação e relicitação) buscam romper com o modelo tradicional e burocrático que afeta a atividade gerencial no país. Logo, a Lei $n^{\circ} 13.448 / 17$, ao instituir o Programa de Parcerias de Investimentos, se traduz em um marco para o processo de 
desenvolvimento da infraestrutura de transportes no país, a qual ainda está distante de atingir padrões satisfatórios, mas que não ficou completamente olvidada pelo Poder Público.

Por fim, reafirma-se a necessidade em definir uma estratégia nacional de desenvolvimento que permita o estabelecimento de um plano real de integração dos modais de transporte, pois sua inexistência, tal como ocorre atualmente, pode ser capaz de ensejar a repetição dos problemas destacados.

Em outras palavras, para que a realização de parcerias entre o Poder Público e a iniciativa privada se mostre realmente eficiente, faz-se essencial evidenciar os fins buscados pelos projetos contratados, de modo que estes integrem um conjunto logístico que favoreça o desenvolvimento da atividade econômica no mercado interno e amplie a competitividade do país em relação ao mercado externo.

\section{CONSIDERAÇÕES FINAIS}

Como destacado, o desenvolvimento compreende um importante objetivo a ser alcançado pelo Estado, sendo, o mercado, uma das ferramentas que viabilizam tal condição. Para isso, compreender as causas do subdesenvolvimento torna-se essencial, de modo que se possa sanar as falhas causadoras da estagnação econômica.

Contudo, a infraestrutura de transportes é um elemento essencial na organização da economia moderna, haja vista as operações negociais globalizadas demandarem eficiência por parte dos agentes econômicos.

Entretanto, inexiste eficiência na infraestrutura de transportes sem haja uma sólida estratégia de desenvolvimento, capaz de integrar os diferentes modais em atendimento aos interesses públicos.

O Brasil, por questões históricas e políticas, conta com modais sucateados e não integrados, o que enfraquece o mercado interno, além de tornar o setor pouco atrativo para a percepção de investimentos públicos e privados, ante o risco envolvido.

De qualquer modo, a tão necessária reestruturação dos modais brasileiros demandará significativo aporte de capital, para o qual, é imprescindível a participação dos agentes privados, em parceria com o Poder Público, através dos contratos de Parcerias Público-Privadas, visando, com isso, pulverizar os riscos e dividir as benesses.

Somado a isso, deve-se repensar o modelo regulatório utilizado no país, se necessário, adequando as concessões já realizadas à estratégia de desenvolvimento nacional, de modo a torná-las verdadeiros instrumentos na promoção do desenvolvimento, assegurando, inclusive, a competição na utilização dos modais.

Assim, o Programa de Parcerias de Investimentos surge como uma tentativa do Poder Público de desburocratizar e integrar o sistema de transportes brasileiro, ante o seu caráter estratégico, com o auxílio de capital privado.

Destarte, nota-se que não é uma tarefa simples, mas é necessária para o aprimoramento da logística nacional, reduzindo a sobrecarga do modal rodoviário, além de contribuir para o 
fortalecimento do mercado interno.

\section{REFERÊNCIAS}

ARAGÃO, Alexandre Santos de. Empresas estatais: o regime jurídico das empresas públicas e sociedades de economia mista. São Paulo: Forense, 2017.

BAGNOLI, Vicente. Direito econômico e concorrencial. 7. ed. São Paulo: Editora Revista dos Tribunais, 2017.

BRASIL. Constituição. Constituição da República Federativa do Brasil de 1988. Brasília: DF: Presidência da República, 1988. Disponível em: http://www.planalto.gov.br/ccivil_03/ constituicao/constituicao.htm. Acesso em: 16 jul. 2021.

BRASIL. Lei $\mathbf{n}^{0} \mathbf{1 0 . 2 3 3}$, de 5 de junho de 2001. Dispõe sobre a reestruturação dos transportes aquaviário e terrestre, cria o Conselho Nacional de Integração de Políticas de Transporte, a Agência Nacional de Transportes Terrestres, a Agência Nacional de Transportes Aquaviários e o Departamento Nacional de Infra-Estrutura de Transportes, e dá outras providências. Brasília, DF: Presidência da República, 2001. Disponível em: http://www.planalto.gov.br/ccivil_03/leis/ leis_2001/110233.htm. Acesso em: 18 jul. 2021.

BRASIL. Lei $\mathbf{n}^{\mathbf{0}} \mathbf{1 3 . 3 3 4}$, de 13 de setembro de 2016. Cria o programa de parcerias de investimentos - PPI; altera a Lei $n^{\circ} 10.683$, de 28 de maio de 2003, e dá outras providências. Brasília: Presidência da República, 2016. Disponível em: http://www.planalto.gov.br/ccivil_03/_ ato2015-2018/2016/Lei/L13334.htm. Acesso em: 30 jul. 2021.

BRASIL. Lei $\mathbf{n}^{\mathbf{0}}$ 13.448, de 05 de junho de 2017. Estabelece diretrizes gerais para prorrogação e relicitação dos contratos de parceria definidos nos termos da Lei n ${ }^{\circ} 13.334$, de 13 de setembro de 2016, nos setores rodoviário, ferroviário e aeroportuário da administração pública federal, e altera a Lei $\mathrm{n}^{\mathrm{o}} 10.233$, de 5 de junho de 2001, e a Lei $\mathrm{n}^{\circ}$ 8.987, de 13 de fevereiro de 1995. Brasília: Presidência da República, 2017. Disponível em: http://www.planalto.gov.br/ccivil_03/_ ato2015-2018/2017/lei/113448.htm. Acesso em: 17 jul. 2021.

BRASIL. Lei n 13.844, de 18 de junho de 2019. Estabelece a organização básica dos órgãos da Presidência da República e dos Ministérios; altera as Leis nos 13.334, de 13 de setembro de 2016, 9.069, de 29 de junho de 1995, 11.457, de 16 de março de 2007, 9.984, de 17 de julho de 2000, 9.433, de 8 de janeiro de 1997, 8.001, de 13 de março de 1990, 11.952, de 25 de junho de 2009, 10.559, de 13 de novembro de 2002, 11.440, de 29 de dezembro de 2006, 9.613, de 3 de março de 1998, 11.473, de 10 de maio de 2007, e 13.346, de 10 de outubro de 2016; e revoga dispositivos das Leis nos 10.233, de 5 de junho de 2001, e 11.284, de 2 de março de 2006, e a Lei $\mathrm{n}^{\mathrm{o}} 13.502$, de $1^{\circ}$ de novembro de 2017. Brasília, DF: Presidência da República, 2019. Disponível em: http://www.planalto.gov.br/ccivil_03/_Ato2019-2022/2019/Lei/L13844. htm\#art85. Acesso em: 18 jul. 2020.

BRESSER PEREIRA, Luiz Carlos. Gestão do setor público: estratégia e estrutura para um novo Estado. In: BRESSER PEREIRA, Luiz Carlos; SPINK, Peter Kevin (org.). Reforma do estado e administração pública gerencial. Tradução Carolina Andrade. 7. ed. Rio de Janeiro: Editora FGV, 2006. 
CARVALHO, Alexandre Xavier Ywata. et al. Caracterização do fluxo de cargas e indicadores de concorrência entre os portos brasileiros. Brasília: IPEA, 2015. Disponível em: http:// repositorio.ipea.gov.br/handle/11058/4371. Acesso em: 23 maio 2020.

CARVALHO, André Castro. Direito da infraestrutura: perspectiva pública. São Paulo: Quartier Latin, 2014.

FURTADO, Celso. Desenvolvimento e subdesenvolvimento. Rio de Janeiro: Contraponto: Centro Internacional Celso Furtado, 2009.

FURTADO, Celso. Alienação do poder econômico. In: D'AGUIAR, Rosa Freire (org.). Essencial Celso Furtado. São Paulo: Penguin Classics Companhia das Letras, 2013.

GALVÃO; Olímpio J. de Arroxelas. Desenvolvimento dos transportes e integração regional no Brasil: uma perspectiva histórica. Planejamento e políticas públicas, Brasília, n. 13, jun. 1996. Disponível em: http://repositorio.ipea.gov.br/handle/11058/4015. Acesso em: 23 maio 2020.

GRAU, Eros Roberto. A ordem econômica na Constituição de 1988. 17. ed. São Paulo: Malheiros, 2015.

JESUS, Michael de. Direito portuário no Brasil. São Paulo: Quartier Latin, 2018.

MARQUES NETO, Floriano de Azevedo. Parte IV - Regulação. In: MARQUES NETO, Floriano Peixoto de Azevedo; KLEIN, A. L. (org.). Tratado de direito administrativo - funções administrativas do Estado. 2. ed. São Paulo: Thomson Reuters Brasil, 2019. v. 2, p. ini-fin.

NAKAMURA, André Luiz dos Santos. Infraestrutura de transportes. Curitiba: Juruá, 2019.

NOHARA, Irene Patrícia. Reforma administrativa e burocracia: impacto da eficiência na configuração do direito administrativo brasileiro. São Paulo: Atlas, 2012.

NÓBREGA, Marcos. Direito da infraestrutura. São Paulo: Quartier Latin, 2011.

OLIVEIRA, Jeferson Sousa. Direitos Humanos como ordenadores da atividade econômica no Brasil. Curitiba: CRV, 2020.

SCHWAB, Klaus. The global competitiveness report 2019. Geneva: World Economic Forum, 2019. Disponível em: http://www3.weforum.org/docs/WEF_ TheGlobalCompetitivenessReport2019.pdf. Acesso em: 22 maio 2020.

SEN, Amartya. Desenvolvimento como liberdade. Tradução Laura Teixeira Motta. São Paulo: Companhia das Letras, 2010.

TAVARES, André Ramos. Direito constitucional econômico. 3. ed. São Paulo: Método, 2011.

TAVARES, André Ramos. Acesso especial à infraestrutura rodoviária e práticas administrativas inconstitucionais. Revista do Direito Administrativo e Infraestrutura, São Paulo, v. 1, p. 2338, abr.jun. 2017. 
UNGER, Roberto Mangabeira. A alternativa nacional e o setor de infraestrutura. Revista do Direito Administrativo e Infraestrutura, São Paulo, v. 1, p. 23-38, abr./jun. 2017.

Como citar: OLIVEIRA, Jeferson Sousa; BENACCHIO, Marcelo. Infraestrutura de transportes: reestruturação como política de desenvolvimento no Brasil. Scientia Iuris, Londrina, v. 25, n. 2, p. 62-82, jul. 2021. DOI: 10.5433/21788189.2021v25n2p62. ISSN: 2178-8189.

Recebido em 23/09/2020

Aprovado em 19/07/2021 